\title{
NUEVAS NOTAS ACERCA DE UNA ANTIGUA RELACIÓN: ORALIDAD Y LITERATURA. EL CASO DE LA INTERROGACIÓN
}

\author{
PATRICIA CÓRDOVA ABUNDIS \\ Universidad de Guadalajara
}

A la memoria de
ANa María Vigara TAUSTE

\section{INTRODUCCIÓN}

Hace ya algunos años, el escritor mexicano Gustavo Sainz revelaba, en el marco de una conferencia en la Feria Internacional del libro en Guadalajara, que para escribir su aclamada novela La princesa del Palacio de Hierro ${ }^{1}$ había adquirido la afición de ir a un Sanborns de la ciudad de México, instalarse en una de sus mesas, fingir que estaba sumergido en la lectura, y dedicarse a registrar expresiones de las mujeres "bien" que ahí se daban cita para conversar. Sin duda, la verosimilitud novelística de Sainz estaba no solo en la sucesión de acciones y estructura del texto, sino en el haber nutrido a sus personajes de un lenguaje que recreaba el habla real de las mujeres que visitaban los lujosos almacenes de la capital mexicana. Una idea aproximada es la de Gabriela Polit al analizar la narrativa del narcotráfico en Colombia y en México. Inspirada en Walter Benjamin, plantea que la principal fuente de los grandes contadores de historias es la experiencia compartida por boca propia. La idea le sirve para explicar el impacto lingüístico de la narrativa de Élmer Mendoza, quien le afirmó, a la profesora de la Universidad de Texas, en Austin, que la lengua utilizada en Un asesino solitario ${ }^{2}$ era la lengua con la que había crecido, la lengua de su madre (Polit, 2013: 15).

${ }^{1}$ La princesa del Palacio de Hierro, novela publicada por Gustavo Sainz en 1974. El Palacio de Hierro es un conocido almacén de lujo que originalmente solo existía en la capital mexicana. Sainz es conocido, junto con José Agustín, como el creador de la literatura de la onda, en México, una literatura que se concentra en la vida juvenil, la vida urbana y la vida de la contracultura mexicana.

${ }^{2}$ Aunque la novela fue originalmente publicada en 1999 por Tusquets Editores, las referencias a la novela, a lo largo del artículo, se remiten a la siguiente edición: É. Mendoza, Un asesino solitario, México, Tusquets Editores México, 2013. 
Pero afirmar que el valor de la oralidad en las narraciones se limita a un fin estilístico en sí mismo, que contribuye fuertemente a la verosimilitud literaria, es dejar en la superficialidad un hecho cuya profundidad es terreno prometedor para el análisis. Conviene subrayar al respecto dos ideas. La primera: existe una correlación entre la oralidad y el contexto social, cultural y cognitivo de los hablantes que permite establecer vínculos sugestivos entre los recursos lingüísticos usados y su significación social. La segunda: la naturaleza propiamente lingüística de los textos orales ${ }^{3}$, que permite apreciar cómo el sistema de la lengua se abre a la creatividad más allá de las restricciones que suelen prevalecer en los textos escritos canónicos, sigue siendo el principal medio con el que el escritor de literatura puede poner en acción no solo personajes verosímiles, sino realistas. Aunque no perdemos de vista, como bien ha señalado Manuel Seco (1983), que no existe una narrativa magnetofónica porque por más que el escritor se nutra del habla coloquial, ya la selección misma, la adaptación de la oralidad a los fines y necesidades de la obra literaria en sí, establece diferencias entre el lenguaje que se realiza en un contexto de aquí y ahora, y la adaptación del mismo al lenguaje literario. En ese mismo sentido, Antonio Narbona insiste en que "[...] no es posible, en rigor, la transposición (o trasplante) de un nivel de habla como el coloquial a otro, el literario, de condiciones y circunstancias comunicativas radicalmente diferentes [...] (1992: 669)

Las variantes de oralidad más fáciles de reproducir son las léxicas y fonéticas porque las mismas no implican una alteración del paradigma escritural sintáctico. En contraste, la particular naturaleza accidentada de la sintaxis oral es la causa de que el escritor no pueda plasmarla tal cual en el diálogo literario. Las continuas elisiones, las iteraciones, la incrustación de partículas lingüísticas con aparente desconexión en el contexto inmediato, el cojeo estructural en sí de la forma oracional canónica de acuerdo a los modelos escriturales, adquieren sentido en el habla gracias a la entonación y los gestos del hablante, y gracias al contexto situacional en el que están inmersos los comunicantes. La situación de aquí y ahora contribuye a que la afectividad y receptividad se antepongan al canon escritural y al objetivo informativo. Ante esto, el escritor se vale de la descripción para otorgar algunos datos ambientales y paralingüísticos con los que contextualiza los coloquios (Poyatos, 2004). No obstante, en la comunicación literaria no es fácil sostener la particular concatenación sintáctica de la oralidad porque no existe el tono y gesto de los hablantes que es señal y signo de la forma en que se está emitiendo y recibiendo la expresividad entre los parlantes. Lo que es coherente y adecuado en la oralidad, no lo es en la escritura.

\footnotetext{
${ }^{3}$ Para una revisión de las distintas tendencias en los estudios de la oralidad véase Luis Cortés (1994) y (2002).
} 
En ese sentido, la variante léxica y la fonética sirven como elementos efectivos, aunque periféricos, con los que el escritor caracteriza la informalidad, la pertenencia social y la cultural de un personaje. Aunque un abuso de este recurso puede llevar al tipismo y su presencia en el texto literario no garantiza que el escritor comunique ni las acciones ni los argumentos propios del grupo social que caracteriza. Hace falta que el escritor utilice dosis precisas de esa "sintaxis liberada de los cánones de la lengua escrita" (Seco, 1983: 18) y que se capten las formas de pensamiento tantas veces estereotipado que fluyen en las conversaciones espontáneas propias de comunidades lingüísticas específicas y contextos comunicativos concretos, para que la recreación oral sea un vehículo dinámico y vivo de elementos socio-culturales y cognitivos propios de los contextos reales que recrea.

Más allá del tipismo, más allá de un realismo superficial, el lenguaje oral de una comunidad lingüística, recreado en la literatura, constituye una riqueza con posibilidades analíticas porque captura prototipos lingüísticos establecidos histórica y geográficamente. Además, la oralidad abre el sistema de la lengua, lo fractura, y, en ese sentido, abre campos de investigación que prometen hallazgos innovadores porque albergan la posibilidad de explicar no lo estático, sino lo dinámico de cualquier lengua. En suma, tanto la oralidad cotidiana como la recreada en la literatura representan la oportunidad de explicar cómo se construyen los argumentos y el estilo en grupos culturales específicos.

La narrativa de Élmer Mendoza tiene el mérito no solo de reproducir variantes de la llamada lengua culichi (sinaloense), sino de hacer confluir diversas jergas características del habla mexicana. Pero su obra, lejos de limitarse a un ejemplo de tipismo, logra asimilar variantes morfosintácticas cuya complejidad radica no en el contenido de las mismas, sino en el uso estratégico que hace de estas en el relato coloquial de un asesino que decide confiar a sus interlocutores - un compañero de trabajo y el lector- cómo fue contratado para asesinar a un candidato a la presidencia de México. La fluidez discursiva del narrador, el asesino Yorch Macías, se logra gracias a que Élmer Mendoza capta no solo el pensamiento aparentemente banal de un asesino solitario, sino un conjunto de argumentos que pueden identificarse como propios de grupos sociales específicos y una ágil esgrima conversacional entre el narrador consigo mismo, entre el narrador y un interlocutor fantasma -que incluye al lector-, y entre los personajes mismos. Es decir, Élmer Mendoza ha sido capaz de dar forma a un personaje de conversación desenvuelta, de pensamiento pragmático, que de acuerdo a las necesidades coloquiales no solo utiliza variedades propias del habla mexicana, sino que refleja tendencias argumentativas superficiales propia de la era global. 


\section{EXPRESIVIDAD E INTERROGACIÓN}

Como ha afirmado Vigara Tauste (1997), la lógica bien estructurada propia de la escritura se debilita cuando se trata de recrear la oralidad en la literatura. El lenguaje de Yorch Macías, en Un asesino solitario, es relevante porque utiliza diversas estrategias propias de la oralidad y porque contiene tendencias del español popular hablado en México por distintos grupos sociales. Revisaremos, en particular, la interrogación como uno de los recursos lingüísticos con los que Élmer Mendoza logra construir esa apariencia de habla fresca. Pero antes puntualicemos cómo la afectividad o expresividad suele sobreponerse en el habla y cómo la misma suele tener matices característicos en distintas comunidades lingüísticas.

Desde Werner Beinhauer, con su obra El español coloquial, originalmente publicada en alemán, en 1930, se ha venido mencionando la relevancia de la afectividad o expresividad que sucede en el habla coloquial y, de manera más enfática, en el español coloquial. Más allá de explicar la expresión afectiva como propia del hablante que pretende apelar a lo que su interlocutor valora, aprecia o desprecia, el hablante de español peninsular es distinguido por Beinhauer de la siguiente manera:

Pues bien: a nadie que conozca, siquiera superficialmente, el carácter subjetivo y apasionado del español de tipo medio, le podrá sorprender el hecho de que los medios para la expresión afectiva de su lenguaje sean particularmente ricos y variados. Es más: me atrevo a afirmar que de todos los pueblos, incluso meridionales de Europa, el español se lleva la palma en este aspecto. Agréguese a ello una extraordinaria fuerza imaginativa y creativa, unida a una capacidad para la improvisación igualmente única, y comprenderemos que el estudio de su lenguaje afectivo, con sus innúmeras comparaciones, interjecciones, hipérboles, imágenes, etc., haya de quedar forzosamente incompleto (Beinhauer, 1978: 196).

No hay duda sobre las diferencias en el carácter social de los distintos grupos culturales comúnmente identificados por regiones o grupos sociales. Existe un espíritu vernáculo que se concretiza en las actitudes lingüísticas y las formas particulares de utilizar las tendencias propias de la oralidad en cualquier lengua. Son múltiples los ejemplos que se pueden dar. Pensemos en el manejo del silencio cuya utilización ha sido, por ejemplo, distinguida entre hablantes occidentales y hablantes de apache en Norteamérica. Peter Burke, siguiendo al antropólogo Keith Basso, advierte cómo el apache decide callar en situaciones en las que el hablante occidental regularmente tendería a hablar para aclarar lo que piensa (1996: 155). De igual manera, Debora Tannen (1994) muestra cómo el silencio puede ser marca propia -aunque no exclusiva- de un grupo o clase social. Ante ciertas 
circunstancias: las mujeres obreras tenderían a hablar más que sus maridos; aunque, en condiciones particulares sucedería lo contrario: el silencio del marido no significaría sumisión, sino un medio para someter. Así, el silencio puede ser, paradójicamente, una marca de afecto o poder. En suma, el silencio -como cualquier otro recurso lingüístico- puede ser explicado a la luz de un contexto diafásico: la oralidad, o a la luz de contextos diastráticos o diatópicos: la pertenencia social o regional, respectivamente.

Vigara Tauste identifica la expresividad como "la huella que queda en la comunicación lingüística de la afectividad del hablante, por la cual éste se convierte a su vez, para su interlocutor, en 'referente' de la comunicación" (1997: 5). En ese sentido, la afectividad actúa como el más importante principio en la organización discursiva, en el habla coloquial, y se aprecia -según Vigara Tauste- en la modalidad oracional, la construcción sintáctica del mensaje y el énfasis semántico ${ }^{4}$. Aunque algunos analistas ${ }^{5}$ no aprueban considerar la afectividad o expresividad del hablante como el motor de un conjunto de fenómenos lingüísticos propios del habla coloquial, consideramos que en el habla coloquial prototípica, es decir, aquella que se caracteriza por un alto grado de espontaneidad, los participantes en el acto comunicativo sí tienden, en mayor o menor medida, a sobreponer la receptividad emotiva en su conversación. Cuando los hablantes están colocados en la situación de aquí y ahora, informal, responderán no solo con base a las expectativas informativas, sino con base en las expectativas

${ }^{4}$ Esta tesis la desarrolla de manera extensa a partir de ejemplos del habla coloquial en su Morfosintaxis del español coloquial (1992). Vigara Tauste (1997) también desarrolla la misma tesis, de manera sintética y aplicada a la novela Miau de Pérez Galdós.

${ }^{5}$ Por ejemplo, Antonio Narbona (1997) considera como un estancamiento teórico y metodológico el que se considere a la expresividad como uno de los principios que rigen el habla coloquial. La comodidad y la adecuación serían otros de estos principios que no están del todo claros. En este trabajo partimos de que lo trascendente, para el análisis del registro coloquial, es que existe una atenuación de la función informativa y de la ordenación lógica verbal, como ha sido constatado en las ya numerosas investigaciones sobre oralidad. Dicho debilitamiento del modelo escritural, que tiene su fundamento en un canon lógico de la lengua, es un hecho lingüístico con variantes propias que funcionan al margen de los principios que lo motivan. La discusión sobre tales principios tendría que enmarcarse en una discusión lingüística-filosófica, e incluso psicológica, que -desde nuestro modesto punto de vista-, no impacta, de manera directa, en el análisis de las tendencias lingüísticas orales. Por otro lado, el texto literario analizado aquí, Un asesino solitario de Élmer Mendoza, permite constatar que las interrogaciones, de clara impronta coloquial, son frecuentemente motivadas por la expresividad (afectividad) del personaje-narrador. Estamos ante un narrador autodiegético que representa a un asesino no frío, ni cerebral, sino dubitante y pasional, entre otros. En conclusión, sí es necesario indagar formalmente sobre los principios que rigen las tendencias lingüísticas orales, pero esa carencia teórica no debilita la noción de que las tendencias orales están regidas por elementos subjetivos que incluyen la actitud psicológica de los hablantes hacia el tema, hacia los interlocutores, hacia los contextos implicados, entre otros. 
pragmáticas que están determinadas social y culturalmente y que impactan no solo en su lado racional, sino en su lado afectivo. Las características prototípicas del habla espontánea así lo advierten: las elisiones, las repeticiones, la fragmentación y dislocación sintáctica, el énfasis morfológico o léxico, entre otros.

Desarrollamos a continuación una aproximación analítica a una forma de la modalidad: el preguntar. La modalidad es considerada la forma más evidente con la que el hablante muestra su actitud. Según Criado de Val (1980), la interrogación contribuye a generar una tensión informativa en el coloquio. Aunque, desde su perspectiva, existe en general una tensión coloquial que sucede en lo informativo, lo dialéctico y lo afectivo. Criado de Val considera que "la interrogación es la más plena y característica modalidad del coloquio, la que mejor define su doble y unitaria estructura" (1980: 45). Así es porque, como también señala Vigara Tauste (1992, 1997), la modalidad interrogativa implica una deixis de la enunciación: se pregunta a alguien. No importa que la pregunta sea lanzada retóricamente, o que el hablante se pregunte mono-dialógicamente a sí mismo. El preguntar es la consideración concreta o abstracta de un interlocutor.

Manuel Seco hace anotaciones sobre la interrogación retórica en Entre visillos de Carmen Martín Gaite. La considera como un recurso enfático de la lengua coloquial. Entre las formas que registra están las siguientes. A través de interrogación retórica, el hablante no espera una respuesta y puede ser dirigida a sí misma, por parte de quien formula la pregunta; el hablante dirige su pregunta a la segunda persona para reclamar su atención, pero él mismo se autorresponde; o el hablante utiliza esquemas coloquiales en los que se gramaticaliza la forma interrogativa y da como resultado una afirmación, por ejemplo: ella quéva a esperar, tú qué vas a saber o qué se yo (Seco, 1983: 363-364). La clasificación que hace Manuel Seco, en este caso, obedece a las necesidades de un fragmento de la novela que está analizando, Entre visillos de Carmen Martín Gaite. Por su parte, en un análisis comparativo entre un texto literario y un texto conversacional obtenido de una entrevista, Vigara Tauste encuentra en la transcripción oral cuatro tipos de interrogaciones:

a) las preguntas que buscan información y piden una respuesta concreta,

b) las preguntas-eco de carácter fático-empático,

c) las preguntas repetidas de otra manera (con distintas palabras) y

d) las preguntas y sugerencias truncadas (Vigara Tauste, 1998: 140-141).

Como puede observarse, la interrogación retórica no aparece en esta clasificación de Vigara Tauste, situación que podría explicarse parcialmente porque la clasificación está construida con respecto a una entrevista 
abierta. En contraste, en el texto literario el control del autor sobre las voces narrativas permite que la pregunta retórica sea no solo un medio de enfatización, como señala Manuel Seco, sino como un medio que garantiza la fluidez monológica o dialógica en el texto narrativo y permite una acentuación del carácter de los personajes. La pregunta retórica permite insinuar la consideración del otro, pero asegura el mantenimiento del foco enunciativo, tanto de quien habla como de quien aparentemente escucha.

En la voz narrativa de Un asesino solitario, Yorch Macías, la interrogación aparece como un recurso estilístico que cumple esencialmente con dos funciones: humanizar al personaje principal, el sicario, y naturalizar el lenguaje con una fluidez sorprendente. Ambas funciones contribuyen a la verosimilitud de lo planteado en la novela. El personaje se humaniza a través del diálogo porque se configura como un asesino que dialoga consigo mismo, que confiesa sus vicisitudes laborales como sicario, y que duda, imagina y especula sobre sus actos a través de la interrogación. A su vez, las constantes preguntas aparecen como medio de naturalización porque el lenguaje dialógico presentado no es estructurado solo en base a enunciados asertivos y afirmaciones argumentativas. Dicha humanización y naturalización tiene un fondo afectivo, expresivo, que se manifiesta no solo en el acto de preguntar, sino en el contenido mismo de las preguntas, en el registro informal del léxico utilizado. De igual manera, según podrá observarse, en la agrupación de las preguntas se pueden entrever algunos argumentos superficiales que representan tendencias de este desafortunado grupo social asentado en México en los últimos años: los sicarios.

\section{El DiÁlOGO ENTRE NARRADOR-INTERLOCUTOR (PERSONAJE FANTASMA Y LECTOR)}

Según se ha establecido, la selección de la modalidad enunciativa es la marca más evidente de la actitud del hablante con respecto a lo que dice: dudar, afirmar, admirarse, preguntar, son selecciones que muestran la posición intelectual y afectiva del emisor con respecto a lo dicho. En Un asesino solitario, la interrogación juega un papel esencial en la expresividad del personaje principal que es a su vez un narrador intra y autodiegético. Yorch Macías es un sicario que, después de una temporada sin empleo, es contactado para asesinar a un candidato presidencial ${ }^{6}$. La novela es la narración

\footnotetext{
${ }^{6}$ La novela está inspirada en el magnicidio que tuvo lugar en 1994, en el marco de las elecciones presidenciales en México. Luis Donaldo Colosio, candidato del PRI, fue asesinado en Tijuana, Baja California, por un asesino al que se le atribuye haber actuado en solitario.
} 
que el protagonista hace de tal suceso, con retrospectivas diversas. Su relato lo hace a un bato ${ }^{7}$, carnal $^{8}$, que camella ${ }^{9}$ igual que él, pero del cual nunca sabemos su precisa identidad, ni participa en la trama más allá de ser un interlocutor difuso. Sin embargo, la estrategia permite al autor utilizar a la modalidad interrogativa como un recurso propio de la oralidad, con el cual construye un diálogo -ficticio, en este caso- impregnado de habla informal, espontaneidad, y, sobre todo, establece un juego espejo en el que el interlocutor difuso parece ser simultáneamente el lector. Con esta estrategia, se garantiza el juego de un interlocutor que no solo lee las palabras que tiene frente a sí, sino que las escucha. Veamos algunos de estos ejemplos que se extienden a lo largo de la novela.

Las primeras líneas del texto son las siguientes:

¿Sabes qué carnal? Durante el año tres meses y diecisiete días que llevamos camellando juntos te he estado wachando ${ }^{10}$ wachando y siento que eres un bato acá, buena onda, de los míos, no sé cómo explicarte, es como una vibra carnal, una vibra chila que me dice que no eres chivato y que puedo confiar en ti, a poco no (pág. 9).

Con la interrogación inicial, el narrador logra situar, aunque ficticiamente, una condición de aquí y ahora característica del habla coloquial. Pero no es solo el hecho de que sea una pregunta lo que permite formar esa situación ficticia de informalidad coloquial. También impacta el lenguaje seleccionado: un verbo de pensamiento, "saber", con un vocativo sumamente informal, "carnal”, popular entre algunos sectores de clase media baja y baja mexicana, que significa "hermano". En el mismo párrafo se puede apreciar el uso de una interrogación que, no obstante omite los signos interrogativos respectivos, el lector infiere que es una pregunta: "a poco no”. En este caso, se trata de una marca fuertemente antropocéntrica, pues al tiempo que parece imponer la perspectiva del hablante, del narrador,

En la novela de Élmer Mendoza, toda la acción sucede en Sinaloa porque se supone que este fue el plan A que falló y que sería remplazado por el plan B, que sucedió en Tijuana, y a través del cual se materializa finalmente el asesinato. Más allá del evento histórico que se recrea en esta novela, la resonancia sociolingüística e histórica de la obra es tremenda, pues a partir del siglo Xxi, México se percataría de la existencia de capas sociales que se conformaron con y para el ejercicio del narcotráfico. Los sicarios, asesinos pagados a sueldo, son un grupo social latente en el actual panorama social y económico. En esta novela se recrean elementos esenciales de la naturaleza idiomática e ideológica de estos grupos.

${ }^{7}$ bato: cuate, amigo. Aunque el diccionario de la RAE define el término como "hombre rústico o tonto", no necesariamente es así. En México es un vocativo que utilizan los jóvenes sin que necesariamente tenga significado negativo.

${ }^{8}$ carnal: hermano. Propio de habla marginal, o con tono juvenil.

9 camellar: trabajar.

${ }^{10}$ wachando: mirando. 
apela a la consideración y aprobación del interlocutor: el personaje compañero de trabajo y, por efecto de espejo, el lector.

En la misma página, entrelazadas con apreciaciones sobre su trabajo en el "drenaje profundo", en actividades ilegales, e indicios que aluden al contexto físico que les rodea, el narrador pregunta: “¿quieres más tequila?” y vuelve al uso de la pregunta como un indicador enunciativo: "¿Y cuál es el rollo ${ }^{11}$ ? Barrientos carnal, ¿te acuerdas de Barrientos? ¿Aquel candidato chilo $^{12}$ a la presidencia?" (2001: 11). El interlocutor supuesto nunca contesta y el lector juega el papel de testigo de una conversación en la que, finalmente, él mismo acaba jugando también el rol de interlocutor de Yorch Macías. Otras preguntas en las que el lector debe inferir la respuesta por el contexto inmediato y mediato de la novela son las siguientes:

1. ¿quieres una cerveza de una vez o hasta que te acabes el tequila? ¿Prefieres gallo ${ }^{13}$ ? (pág. 48)

2. Por cierto, apenas probaste los tamales, ¿qué onda no te gustaron? Ah, simón ${ }^{14}$, al rato los calentamos(...) (pág. 49)

3. La guerra de las galaxias, ¿la viste carnal? (pág. 61)

4. De mendigo a millonario con Eddie Murphy, jla viste? (pág. 95)

5. ¿te gusta la coca ${ }^{15}$ con galletas pancrema ${ }^{16}$ ? (pág. 103)

6. (...) neta que se veían como en la película de King Kong, ¿te acuerdas? (pág. 116)

7. ¿Te acuerdas del San Pancho, aquel cabaret que cerraba a las seis de la mañana y que tenía un ambientazo? (pág. 137)

8. ¿qué onda, vas a mear? Órale, te espero mientras me forjo un gallito (pág. 144)

9. ¿De veras carnal, no se te antoja la coca con galletas pancrema? (pág. 178)

Nótese que estas preguntas no son en sí mismas retóricas porque el lector puede suponer que el personaje fantasma, que funciona como interlocutor primario, sí ha contestado, aunque nosotros, lectores, no seamos testigos de la respuesta de tal personaje.

Con las preguntas retóricas hechas al interlocutor-personaje y fantasma-lector, el narrador imprime una complicidad ${ }^{17}$ que garantiza una co-

11 rollo: tema, asunto.

12 chilo: bonito, agradable.

13 gallo: cigarro de marihuana.

14 simón: sí.

15 coca: refresco de cola.

${ }^{16}$ galletas pancrema: galletas saladas, algunas veces con sabor a queso.

17 Agradezco aquí a mis alumnos del curso Pragmática del Español, en la primavera de 2015, que tuvo lugar en la Universidad de Guadalajara. Con ellos analicé, desde una perspectiva prag- 
municación coloquial íntima con la que, a su vez, se obtiene la concesión de utilizar un lenguaje hipocorrecto plagado de disfemismos propio de grupos criminales y marginales. De tal manera que el lector tiene la impresión de estar inmerso en las entrañas del inframundo criminal cuya cercanía se acentúa con el reconocimiento de otras variantes léxicas propias del habla estándar mexicana. Veamos algunos ejemplos de preguntas retóricas. Cuando Yorch Macías se entera de que le pagarían medio millón de dólares por el asesinato, piensa: “(...) si me ponía buzo podría resolver el problema económico para todos los días de mi vida, casi ni iba a ganar billetes el bato, ¿eh?” (2001: 17-18). Macías se dirige a su interlocutor porque pretende su connivencia y participación tal como sucede cuando, en la vida real, compartimos situaciones personales a través del habla. Cuando Macías narra su reencuentro con Charis, su expareja, ahora casada con Fito, un socialista desencantado de la vida, pregunta a su interlocutorlector: “¿tú entendías algo carnal?” (pág. 25) o "Yo lo escuchaba carnal, ¿pero quieres saber si le entendía algo?, ni madres” (pág. 26).

Cuando existen cambios de tema, el narrador también quiere asegurar la complicidad del interlocutor-lector, con las preguntas retóricas: "¿Sabes qué, carnal? Nunca fui kamikaze, ¿qué provecho tenía hacer un jale bien pagado y bien planeado y quedar ahí nomás con el culo parriba?” (pág. 29). El verbo de pensamiento aparece otra vez en las preguntas retóricas: saber, lo cual enfatiza una apelación a la complicidad intelectual al interlocutor. En los temas frívolos también interpela. Por ejemplo, comparte cómo pasaba el tiempo mientras el interactuaba con el control remoto en sus manos, y pregunta "¿a poco tú nunca te alocaste con el control, carnal? Neta, ¿qué le pasa a uno?” (pág. 32).

A través de las preguntas retóricas dirigidas al interlocutor, el autor además logra una plasticidad dinámica de lo coloquial porque sugiere constantemente la complicidad de quienes escuchan su relato. Estas preguntas se encuentran a lo largo de todo el relato de 228 páginas. En términos generales, se pueden identificar cuatro tipo de preguntas retóricas:

a) es evidente que el interlocutor ficticio o el lector no posee información para la respuesta,

b) el narrador se contesta a sí mismo,

c) marcadores conversacionales apócrifos porque el interlocutor es incierto y

d) el narrador opta por una modalidad de enunciado interrogativa, pero su modalidad de enunciación indica que está afirmando.

mática, el primer capítulo de la novela. Ellos identificaron como una de las intenciones de la voz narrativa el establecer una complicidad con el interlocutor fantasma. Dicha intención de complicidad explicaría el uso de algunas interrogaciones y el uso del lenguaje hipocorrecto. 
a) Es evidente que el interlocutor ficticio o el lector no poseen información para la respuesta

1. ¿sabes cuándo iba a ganar eso trabajando para el jefe H? (pág. 34)

2. ¿y sabes qué seguía en el noticiero? (pág. 35)

3. ¿Sabes cuál iba a ser mi identidad en la selva Lacandona? (pág. 103)

4. ¿quién crees que venía al mando de la perrada, carnal? (pág. 121)

5. ¿quién crees que salió de adentro y se puso a platicar con el Jiménez? (pág. 150)

6. ¿`sabes cómo me iba a llamar? (pág. 188)

7. Estaba en eso cuando ¿quién crees que llegó muy mona a saludarlo? (pág. 192)

8. ¿`sabes cómo se llamaba? (pág. 177)

b) El narrador se contesta a sí mismo

1. (...) y a lo mejor había llegado mi hora, me dije, ¿Sabes qué carnal? estos batos van a quedar para el arrastre" (pág. 61)

2. Ándese paseando, qué colgado, ¿tú crees que hicimos caso? Nel ni madres (...) (pág. 62)

3. ¿Ya te dije cómo me decían, carnal? (...) el Europeo, me decían el Europeo dizque porque tenía varias reglas y me gustaba trabajar solo" (pág. 87)

4. Toda acá, buena onda, fui a abrir y ¿qué crees?, era el pinche Willy. (pág. 166)

\section{c) Marcadores conversacionales apócrifos porque el interlocutor es incierto ${ }^{18}$}

1. ¿qué onda, no? (pág. 83)

2. ¿Sabes cuál era la onda, carnal? (pág. 87)

3. ¿¿sabes qué carnal? (pág. 94) (pág. 185) (pág. 224)

4. ¿Por qué no le entré al narcotráfico? (pág. 113)

5. Tenía la tele prendida en Telemundo, pasaron un agarre machín entre los serbios y los bosnios herzegovinos, oye carnal: ¿y a estos cabrones quien les pagaba?, porque no creo que todo ese desmadre lo hayan hecho gratis, ¿o sî́? (pág. 143)

6. El gimnasio era un edificio con techo curveado, como de almacén, que contenía una cancha de basquet. Me iba a bajar pero nel, ¿y sabes por qué?, chale, ¿a quién crees que fue al primero que waché? A ver, ¿tú que todo lo sabes y lo que no, lo inventas? (pág. 149)

7. Si me ves, jamás piensas que soy guarura, ¿cierto? (pág. 150)

8. ¿¿sabes qué?, estaba cabrón, el olor del Willy era el olor del Willy (...) (pág. 179)

\footnotetext{
${ }_{18}$ Marcadores conversacionales apócrifos porque no hay una respuesta del personaje fantasma ni del lector virtual.
} 
9. ¿Qué por qué te digo todo este salivero? (pág. 180)

10. ¿tú crees? (pág. 189)

11. ¿la has oído carnal? (pág. 190)

12. Ni modo que no me acordara de los buenos momentos ¿verdad? (pág. 204)

13. ¿`sabes qué? (pág. 206) (pág. 211)

14. ¿y sabes cuál era la onda? (pág. 226)

15. ¿no? (pág. 227)

d) el narrador opta por una modalidad de enunciado interrogativa, pero su modalidad de enunciación indica que está afirmando.

1. ¿qué no vivimos en un país libre? (pág. 141)

2. ¿era lo normal, no? Para eso se habían casado (...) (pág. 187)

3. ¿Cuándo oíste o leíste que en Culiacán se iba a hacer el jale ${ }^{19}$ ? ¿Nunca, verdad? (pág. 228)

Como puede observarse, la función prototípica de las preguntas retóricas es la que se atribuye a los marcadores conversacionales que consiste en una función fática, en la intención de garantizar el contacto con el destinatario de la conversación. Las preguntas retóricas dirigidas al interlocutor fantasma-lector tienden a desaparecer cuando, en la narración de Estilo Libre Indirecto, aparece un diálogo monologal que la voz narrativa utiliza para hablar consigo mismo, o cuando tienen lugar los diálogos entre personajes. Con ello, se logra un equilibrio en el recurso de la interrogación. Se revisan a continuación ambos casos.

\section{El diÁlogo NARRADOR-NARRAdOR (MONOLOGAL)}

El diálogo consigo mismo es un recurso que utiliza Élmer Mendoza para mostrar el pensamiento interior del narrador autodiegético y para mantener una fluidez dinámica en la voz narrativa que garantice la atención del lector. La asiduidad de las interpelaciones a sí mismo no tienen, sin embargo, una misma función pragmática a lo largo de la obra literaria. Son cuatro las funciones que sobresalen y están presentadas siguiendo su frecuencia de incidencia, en orden decreciente:
a) Especulativas
b) Reflexivas
c) Imaginarias
d) Reclamo o queja

19 jale: trabajo. 
a) Especulativas. Las preguntas especulativas son las que se presentan con mayor frecuencia, hecho que se explica porque estamos ante una novela que si bien no es estrictamente policiaca o negra, sí es la narración de un magnicidio que aunque ya sucedió en la historia misma, está por suceder en el tiempo de la narración. Las preguntas especulativas humanizan al asesino en el sentido que es recreado como alguien que utiliza la especulación e incertidumbre sobre eventos históricos, sobre experiencias propias, sobre lo que significan los hechos que está presenciando. Con este recurso lingüístico, el personaje narrador no es plano, sino que se muestra impregnado por cierto desconcierto frente a lo sucedido y frente al devenir. Este fenómeno, aunado a las variantes léxicas utilizadas -ya sea en la pregunta misma o en el contexto verbal inmediato-, procedentes de un español informal propio de la jerga culichi ${ }^{20}$, del lenguaje del hampa, o de hablantes cuya identidad lingüística asumida muestra una simpatía por lo marginal o transgresivo, naturaliza el lenguaje de la voz narrativa al grado de -como ya se mencionó- hacer sentir al lector que está escuchando el relato que lee. Veamos algunos ejemplos:

1. ¿qué estaría haciendo la Charis a esa hora?

2. ¿Buscaría a Fabiola? $\mathrm{Nel}^{21}$, a mí esas calenturas se me pasaban de volada. (pág. 109)

3. me acordaba también del Vikingo, ¿qué onda, para qué me buscaba?, de mi Beretta tan querida, del Willy, del Veintiuno, ¿Todavía estaría solita la Charis? (pág. 145)

4. ándese paseando, pensé, ¿de qué se trata, acaso Dios no quiere que me gane estos cueros de rana? (pág. 150)

5. me bajé y lo primero que vi fue el picapón del Willy, estacionado ahí mismo, qué onda, ¿todavía estaba con los tragaldabas? ¿Cuánto tiempo había estado fuera? (pág. 181)

6. qué onda, ¿qué tal si en vez de bajarlo en la cena lo bajaba ahí, mientras corría? (pág. 185)

7. ¿Qué onda con el Willy? ¿Qué relación tenía con Harry y Kalimán? (pág. 195)

8. ¿de qué se trata, qué hace ella aquí? (pág. 203)

9. ¿Para qué quería ver al Veintiuno, acaso no me la había hecho gacha ${ }^{22}$ el güey mandándome a Harry el Sucio y a los otros para que me dieran $\operatorname{cran}^{23}$ ? (pág. 211)

\footnotetext{
${ }^{20}$ culichi: propio de Sinaloa, estado ubicado en el noroeste de México.

21 nel: $n o$.

${ }^{22}$ hacerla gacha: no apoyar, no estar de acuerdo.

${ }^{23}$ dar cran: dar muerte.
} 
Como puede observarse, este tipo de preguntas tienen que ver directamente con el inquirir sobre la razón o naturaleza de hechos concretos. La especulación no se relaciona con situaciones abstractas, sino con la necesidad o curiosidad de esclarecer los móviles de una situación en que se encuentran otros personajes, como la Charis, amante de Yorch Macías.

b) Reflexivas. Otra de las formas de humanizar la voz narrativa, de vitalizar al asesino solitario, es a través de reflexiones que no se caracterizan por el clásico aforismo, la sentencia contundente, o el uso de conectores argumentativos sofisticados. Yorch Macías procede de una capa baja de la sociedad, su procedencia es marginal, por ello abunda la reflexión no como afirmación o argumento estructurado en tesis, evidencias y conclusiones. El argumento aparece con el sesgo de la interrogación que se proyecta a situaciones concretas. Con las interrogaciones reflexivas la voz narrativa pondera, con argumentos elementales, el sentido o trascendencia de un hecho, una situación, o de una persona.

1. Nunca fui kamizake, ¿qué provecho tenía hacer un jale bien pagado y bien planeado y quedar ahí nomás con el culo parriba? (pág. 29)

2. Mientras veía la telera me acordé del Chupafaros, con ganas de tenerlo cerca y decirle, qué onda pues mi Chupa, ¿no que no habría guerrilla en México, no que no?

3. Aquí puedo hacer dos cosas, pensé: pegarle un chinga ${ }^{24}$ de perro bailarín o matarlo, y si lo puedo matar ¿para qué me canso golpeándolo? (pág. 81)

4. ¿qué onda, por qué ese afán de que lo bajara ${ }^{25}$ en público? (pág. 182)

En 1, se implica el argumento: es positivo ser un sicario ("hacer un jale bien pagado"), pero sin llegar al sacrificio. De donde se extiende que no importa la ideología detrás de la violencia, sino la violencia que permite ganar dinero. En 2, el argumento es la guerrilla que existe en México. En 3, la vida humana no tiene valor, hay que matar sin consideraciones. Mientras que en 4, se expresa el desconcierto ante la exigencia de que el candidato sea asesinado en público.

Las preguntas reflexivas que el narrador emite para sí parecen funcionar como mitigadores de un argumento que, dicho afirmativamente, tendría un efecto crudo y duro. Argumentar preguntando, en este contexto, puede sumar el valor de ingenuidad o comicidad a un argumento que de suyo no cuenta con dichos valores, sino que los niega.

\footnotetext{
24 chinga: golpiza.

25 bajar a alguien: matarlo.
} 
c) Imaginarias. Estas preguntas se hacen en el contexto de una situación que la voz narrativa imagina. La pregunta se usa para recrear una situación ficticia dentro de la ficción de la novela. Son una ficción redundante. En ese sentido, es un metadiscurso en el que la pregunta se consolida como parte del estilo del narrador autodiegético. La narración deviene multidimensional y adquiere una plasticidad mayor.

1. en cuanto me ponga en la pista para llegar al campamento de los zapatistas le diré, ¿sabes qué, Timoteo Zopliti?, nada personal bato, pero hasta aquí me sirves, ahora debes reunirte con tus antepasados, y rájale, a cómo te tiente ${ }^{26}$ (pág. 108)

2. me echo el jale y me largo a Chiapas, donde al primer que me voy a dejar caimán va a ser a Timoteo Zopitli, ¿Qué onda mi Timo? (pág. 129)

3. Voy, lo busco, lo encuentro dando clases y a cómo te tiente, cabrón, rájale (...) y la Charis llorando, preguntado ¿Por qué, Yorch, por qué lo hiciste? (pág. 165)

4. Habíamos sido compañeros algún tiempo: ¿Qué onda morros ${ }^{27}$ ?, Macías, ¿tú aquí?, qué sorpresa, diría Harry el Sucio (...) y yo prendido siguiéndoles el rollo, Qué onda, ¿ya conocieron La Ballena? (págs. 175-176)

d) Reclamo o queja. La voz narrativa, Yorch Macías, manifiesta su enojo con respecto a diversos temas. Los más recurrentes son su molestia por la critica que algunos sectores de la sociedad hacen a Televisa, la compañía de medios más fuerte en México; su inconformidad cuando sus deseos no coinciden con los de su amante; y su enojo cuando se percata de que su mejor amigo es cercano a un judicial con el cual él mismo se ha enemistado.

1. Bueno, ¿qué tanto les duelen los televisos ${ }^{28}$, que daño les hacen, a quién han dejado sin comer? lo único que hacen es atender su negocio (pág. 140)

2. Que era cumpleaños del Chupafaros, pues mucho gusto, que lo agasaje en todas las discos de la ciudad, ¿y a mí qué?, ¿qué me miara un perro?, pues fíjate que no, nel ni madres; (págs. 163-164)

3. ¿qué tenía que andar ahí de boca suelta? (pág. 169)

4. ¿por qué tenía que ponerse en ese plan cuando más ganas tenía de verla, de acariciarla, cuando más la necesitaba? (pág. 179)

${ }^{26}$ a cómo te tiente: a lo que te corresponda.

27 morro: niños, jóvenes.

${ }^{28}$ televisos: dueños y trabajadores de Televisa, la compañía de telecomunicaciones más grande en México. 
5. ¿qué chingados tenía que hacer el Willy, que era mi amigo, con estos cabrones? (pág. 179)

Entre las preguntas que se hace a sí mismo Yorch Macías, también aparece una única incidencia de la pregunta prototípica que se hace cuando hay incertidumbre y tras la cual se espera que el interlocutor proporcione información. Sin embargo, se explica su escasez en el discurso monologal del narrador porque él mismo sabe, lógicamente, que carece de la información.

\section{El diálogo Personaje-PERSONAJe}

La gama de preguntas que se realizan entre personajes es muy amplia, pues la misma imitaría, potencialmente, el universo de discurso coloquial que sucede en el mundo real. Las mismas aparecen insertadas en el Discurso Indirecto Libre, como es de esperarse, sin uso de guiones o comillas; lo que provoca que algunas preguntas -en realidad, pocas- queden suspendidas en la ambigüedad de si el narrador las ha extendido al personaje o son preguntas reflexivas que se hace para sí. Si consideramos la obra literaria, en particular la novela, como un acto de habla en que el autor, a través del narrador, establece una comunicación con el lector, las preguntas que aluden a la enunciación en sí son las que hemos revisado antes: las de narrador-interlocutor y las de narrador-narrador. En contraste, en este grupo de preguntas, la enunciación excluye la enunciación de interlocución directa o íntima, en tanto que sucede solo entre personajes. Aunque, sin embargo, dichos diálogos entre personajes repetidas veces incluye al narrador, ya que es autodiegético.

Entre personajes, aparecen preguntas cuya función pragmática es realizar transacciones prototípicas que aluden a la cortesía como el saludar o mostrarse solícito: “¿Y qué desea señor Macías?” (pág. 157). O las referentes a transacciones cotidianas como ofrecer ayuda: "Qué onda, ¿quieres que te lleve a algún lado o qué? (pág. 64); la búsqueda de apoyo: “¿Qué onda, qué te parece?" (pág. 80); o con las que se solicita información: “¿A quién mandaste recado con la Liz?” (pág. 169). Con estas preguntas prototípicas, la voz narrativa coloca, en lo que podríamos llamar una acción modélica, a sus personajes. Además de este tipo de preguntas, aparecen aquellas que se utilizan con funciones pragmáticas específicas. Abordamos solo las que se presentan con mayor frecuencia:
a) Marcadores conversacionales
b) Confirmar
c) Retar 
a) Marcadores conversacionales. La intención enunciativa, entre personajes, es específica. Predominan el uso adverbial de "verdad" y sus variantes populares como "neta". De igual manera es recurrente el uso del verbo de pensamiento "saber".

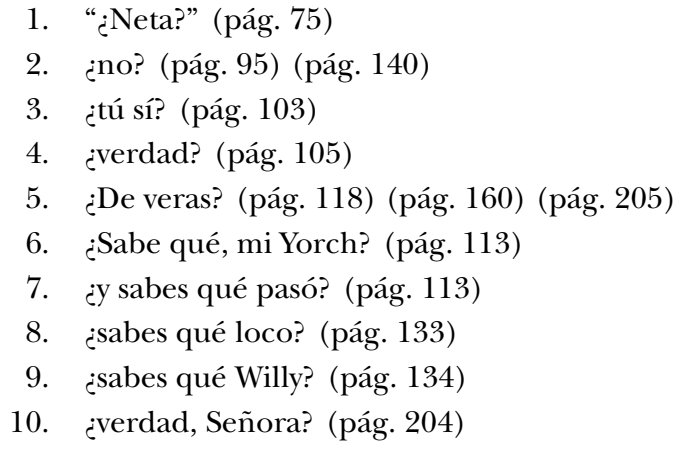

Incluimos aquí las llamadas preguntas eco, cuya función es corroborar lo dicho por el interlocutor o simplemente tomar tiempo para ordenar o frenar la conversación. Se encontraron dos casos:

1. “no se claven, llévame a un hotel, ¿Hotel?” (pág. 127)

2. "Lo que sí te tengo que decir es que el vikingo te anda buscando, ¿Buscándome?” (pág. 133)

b) Confirmar. Aparecen también las preguntas con las que no se pretende simplemente obtener información, sino confirmar una conjetura o sospecha del hablante que pregunta.

1. “Qué onda Yorch, en realidad quién eres, qué pasó en el retén, exactamente en qué trabajas en el gobierno?” (pág. 98)

2. “¿Cómo ves a mi hija, verdad que está bien bonita?” (pág. 100)

3. “¿Le parece que lo busque después de ese tiempo?” (pág. 102)

4. “¿De veras no podría hacerme un campito ${ }^{29}$ ?” (pág. 102)

5. “Chale, ¿cómo así, pinche Willy?, ¿̇e qué se trata?” (pág. 118)

6. ¿Lavar ahí? (pág. 130)

c) Retar. Preguntar para provocar o retar es otra modalidad pragmática que sobresale entre las interrogaciones de los personajes. La tendencia marca no solo el carácter masculino de los personajes, sino la congruencia con el tema de la novela que se desarrolla en los ámbitos del crimen.

${ }^{29}$ hacer un campito: dejar espacio para algo o alguien. 
1. “¿Qué onda mi chuco?, le decías al bato, y él te reviraba bien felón ${ }^{30}$, ¿Qué, no te gustó?, y tú, No pues, no hay bronca bato, no hay problema, y entonces él, Ah ¿no hay problema?, y enseguida se te venía encima con una manopla y una cadena y órale güey, querías divertirte, ahí tienes tu diversión, querías bailar y pasar un buen rato, órales, ahí tienes tu baile.” (pág. 68)

2. “¿y tú que te metes güey, eres su pilmama o qué?” (pág. 70)

3. “¿Viste bien cabrón?, esa es mi identificación, y volví a disparar” (pág. 97)

4. “Órale pinche puto, ¿muy machito, no? ¿Por qué no me sueltas?" (pág. 124)

\section{Conclusiones}

La interrogación es la forma más evidente de alusión a la interlocución, pues es, en sí misma, un referente deíctico a la enunciación. Sin embargo, la forma interrogativa de un enunciado puede contrastar con la modalidad de la enunciación: se puede afirmar preguntando. De la misma manera, la modalidad de enunciado de las preguntas retóricas contrasta con la modalidad de la enunciación. Cuando el hablante o personaje emite preguntas retóricas su posición es, en realidad, monologal y puede obedecer a distintas razones. El hablante o personaje emite preguntas retóricas porque sabe que su interlocutor no tiene la información y él mismo la proporcionará; porque quiere mostrar consideración e inclusión al interlocutor, pero no ceder el turno de habla (ya sea por necesidades dialógicas reales o por estrategia en el discurso literario); o porque con las preguntas retóricas logra un efecto plástico en su posición enunciativa o en la fluidez de su discurso; o, finalmente, porque la pregunta retórica funciona como un ordenador del discurso para el hablante.

Por otra parte, las preguntas que el narrador hace para sí mismo sirven como mecanismos para especular, reflexionar, imaginar o reclamar. El que el autor utilice este recurso en la voz narrativa, como se ha dicho, humaniza al personaje, pero también tiene un claro efecto estilístico. Si el asesino solitario se nos presenta especulando, reflexionando, imaginando o reclamando, todo ello con forma de preguntas, el lector tiene claro que está ante un personaje que no es de una pieza, no es monolítico. El asesino, quien ejerce la violencia pragmáticamente, sin más ideología que la obtención de dinero, tiene fisuras: duda sobre las situaciones y sobre el futuro; reflexiona con argumentos elementales que reflejan su intrascendencia social; cede constantemente a entornos imaginarios que lo muestran

${ }^{30}$ felón: agresivo, provocador. 
como alguien que no tiene los pies en la tierra, que pierde el control de los hechos; pierde los estribos, reclama con el pensamiento y con la exteriorización de su palabra.

La interrogación toma forma como un recurso estilístico y argumentativo. En el primer caso, naturaliza y, en el segundo, humaniza. Cuándo se pregunta, cómo se pregunta, y en dónde se hace, son preguntas que conducen a consideraciones contextuales, tanto verbales como extraverbales, que advierten sobre la diversidad pragmática en el uso de la interrogación.

Otras consideraciones finales sobre la interrogación que han podido constatarse en el presente análisis:

1) La modalidad interrogativa de un enunciado no necesariamente coincide con la modalidad de la enunciación en que se emite dicho enunciado.

2) La pregunta no es esencial para que el evento dialógico acontezca. Por lo tanto, su presencia moderada o reiterada es marca del estilo del hablante, o del escritor -vía voz narrativa-, y de los contextos culturales en que sucede la comunicación.

3) La pregunta retórica tiene distintos móviles, entre los que se encuentran:

a) mantenimiento de turno de habla,

b) ordenación del discurso del hablante,

c) guiño de empatía al interlocutor para asegurar el ser escuchado,

d) para anunciar que proporcionará, al interlocutor, información de la que carece.

4) Es posible que la interrogación contribuya a la fluidez dialógica tanto en el texto literario como en el texto oral. De ahí que sea un recurso estilístico que define al hablante, o pretende asegurar la recepción de la comunicación.

5) El equilibrio de la naturalidad coloquial se logra con la modalidad interrogativa, alternando el diálogo ficticio entre narrador-interlocutor-lector, narrador-narrador y narrador(personaje)-personajes. 


\section{BIBLIOGRAFÍA}

BeInHAuer, W. (1978): El español coloquial, Madrid, Gredos.

Burke, P. (1996): Hablar y callar. Funciones sociales del lenguaje a través de la historia, Barcelona, Gedisa.

CorTÉs, L. (1994): Tendencias actuales en el estudio del español hablado, Almería, Universidad de Almería.

- (2002): Los estudios del español hablado entre 1950 y 1999, Madrid, Arco/Libros.

CRIADO DE VAL, M. (1980): Estructura general del coloquio, Madrid, SGEL.

Narbona, A. (1992): "Notas sobre sintaxis coloquial y realismo en la literatura narrativa española”, en J. A. Bartol Hernández, J. de Santiago Guervós y J. F. García Santos (coords.), Estudios filológicos en homenaje a Eugenio de Bustos Tovar, vol. 2, Salamanca, Universidad de Salamanca.

- (1997): "Breve panorama de los estudios de sintaxis del español coloquial en España”, en La Lingua Spagnola dalla Transizione a Oggi (1975-1995), Italia, Mauro Baroni editore.

Polit, G. (2013): Narrating Narcos. Culiacán and Medellín, Pensilvania, University of Pittsburgh Press.

Poyatos, F. (2004): "Los elementos no verbales en los textos literarios: oralidad inherente y presencia explícita e implícita”, Oralia, 7, págs. 119-148.

SEco M. (1973): "La lengua coloquial: 'Entre visillos', de Carmen Martín Gaite", en El comentario de textos, vol. 1, Madrid, Castalia, págs. 357-375.

- (1983): "Lengua coloquial y literatura", Boletín Informativo de la Fundación Juan March, 129, págs. 3-22.

Tannen, D. (1994): Gender and Discourse, Nueva York, Oxford University Press.

Vigara Tauste, A. Ma (1992): Morfosintaxis del español coloquial. Esbozo estilístico, Madrid, Gredos.

- (1997): "Miau: El lenguaje coloquial humano en Galdós", en Espéculo, número 5. Obtenido el 23 de febrero de 2000 de <https://pendientedemigra cion.ucm.es/info/especulo/numero5/miau_vig.htm>.

- (1998): "Lengua oral y comentario de textos coloquiales", en I. Carrasco y G. Fernández Ariza (eds.), El comentario de textos, Málaga, Analecta Malacitana, Anejo XVII, págs. 117-158.

- (2000): "Sobre la deixis coloquial", en A. Briz, J. R. Gómez Molina y M. J. Martínez Alcaide, Grupo Val.Es.Co. (coords.), Pragmática y gramática del español hablado (Actas del II Simposio sobre análisis del discurso oral), Valencia, Universidad de Valencia/Pórtico, págs. 256-267. 